\title{
A model to evaluate energy efficient spatial structure for transportation via spatially balancing the job - house ratio - The case of Sri Lanka
}

\author{
S.W.M.P. Senevirathne*, P.C.P. De Silva \\ Department of Town \& Country Planning, University of Moratuwa, Moratuwa, 10400, Sri Lanka
}

\begin{abstract}
The trend of haphazard land use practices has caused for a massive cost and a congestion in major transport corridors. In this case, a proper combination of land use distribution will be able to optimize the Vehicle Miles Travelled (VMT) to reduce the transportation-related energy consumption and city congestion. One of the significant approaches of integrating transport and urban development is developing an optimized ratio for administrative level job-house combinations. The objective of this research is to develop a method to identify a job-house ratio for each analysis zones where the road congestion will be optimized. The gravity model is used to perform the trip distribution and it is assigned to the road network using the graph theory. The main assumption taken in the study is that the trip generation by a group of population in a particular area is considered as work based trips. The result of the method for Colombo district indicated that the job-house ratio varies from 0.1 to 9.2 resulting an average trip length of $23 \mathrm{~km}$ between houses to work locations. However, the method suggested a minimum and maximum value of 0.5 and 4 which reduced the VMT from $46 \%$ and average fuel consumption by $22 \%$.
\end{abstract}

Keywords: Job-house ratio, Land use - transport simulation model, Level of Service, Motorized trip distribution, Route assignment

\section{Introduction}

The prevailing urban development trends and patterns in Sri Lanka have paved the way towards many complex and discriminated issues. The disparity in income levels with respect to the working areas has caused for a between-places and within-places energy wastage. Generally, the high income earning community consumes and causes for wasting more energy in urban areas. "The main reasons for congestion are poor city planning, inappropriate public transport facilities and insufficient traffic system, which leads to waste of time, fuel and wear and tear of vehicles," (Kumarage, 2013). In this case, a proper combination of job-housing locations will be able to create an appropriate setting for a city having the Vehicle Miles Travelled (VMT) properly configured to reduce the transportation related energy consumption and city congestion. The research study carried out in the University of Wisconsin, USA has identified that the JobHouse ratio directly affects the VMT in a region and a planned ratio can directly control the region's travel behavior. As a land use policy, balancing job-house ratio in accordance with the region's travel behavior can mitigate road related congestion and environmental impacts (Peng, 1997). Sri Lanka is losing $1.5 \%$ of its annual GDP due to traffic congestion (Kumarage, 2013). According to the sources of Sri Lanka Labour
Department, there are few cities with a higher number of employment concentration and the scale keep growing since the communities are aggregating around the zone (e.g.: Colombo - 3,875,720 / Kandy - 511,341 / Kurunegala - 448,022 / Gampaha - 144,938). Since Colombo is developing as Sri Lanka's major commercial capital, currently there are 7.8 million motorized trips being generated within the Colombo Metropolitan Region (CMR). Approximately 1.4 million trips are generated within the CMR towards the Colombo Municipal Council (CMC). The seven major transport corridors towards CMR carry 100,000 average trips daily for the city where in Galle corridor it is 250,000 and in Avissawella corridor it is 200,000. All these traffic flow towards Colombo city is happening at an average speed of $17 \mathrm{~km} / \mathrm{h}$. The overall VMT within CMR is approximately 95 million $\mathrm{km}$ out of which $40 \%$ are served by the public transport modes. It is estimated that the values are growing by $10 \%$ per annum. Over $40 \%$ of the length of the road network in CMR has the Level of Service below $\mathrm{C}$ which indicates they have reached their design capacity in terms of the traffic volume (Department of Transport \& Logistics Management, University of Moratuwa \& Japan International Cooperation Agency (JICA), 2015). Level-of-service (LOS) is the best known measure for qualitatively 
assessing the quality of a roadway (National Research Council (U.S.), 2000).

The objective of this research is to develop a method to optimize the congestion in road network in the study area by introducing a balanced amount of job-house combinations for each traffic analysis zones (TAZ). As a result of the introduced job-house ratio for each TAZ the traffic congestion and the amount of VMT will be reduced and it will significantly impact on the reduction of transportation related energy.

\section{Relationship between transportation and land use planning}

\subsection{Urbanization Trends}

The today's world is moving towards a globalized and interconnected development. $54 \%$ of the world's population is living in urban areas since 2014, however the levels of urbanization among the cities varies substantially. The urban population has recorded a rapid growth since 1950 up to 3.9 billion. Since 1950 the rural population of the world has grown slowly where it is now approximately 3.4 billion and by 2050 it is expected to decline to 3.2 billion (UN, Department of Economic and Social Affairs, 2014). Under the continuing rate of population growth, within next 30 years there will be an increment of 2.5 billion population in the world's urban areas (UN, Department of Economic and Social Affairs, 2014).

In the Sri Lankan context the urban population is $18.2 \%$ and identified as a low urbanized country relative to the per capita income $(\$ 3,820,2015)$. Western Province is the highest urbanized province $(38.8 \%)$ initiating the urbanization pattern spread along the coastal boarder. The Colombo Metropolitan Region (CMR) covers only $6 \%$ of Sri Lanka's land extent and it occupies $28 \%$ of the country's population, $45 \%$ share of the GDP and $73 \%$ of the industrial production (World Bank \& United Nations Human Settlements Programme, 2012).

As a result of this clustered urban centres, the Sri Lankan cities host a larger floating population. As the largest urban centre, Colombo city attracts approximately 500,000 floating population on any working day. In the CMR, floating population is 10 million per day. Out of this, 7.8 million trips are motorized. The motorized trips are composed of $14 \%$ private cars, $3.4 \%$ trains, $48.1 \%$ bus, $17.9 \%$ motor cycle and $16.6 \%$ taxis (Ministry of Megapolis and Western Region Development, 2016). This concentration in Colombo and surrounding cities has caused for a rapid change in the urban transportation sector throughout the past decade. The continuing growth of traffic congestion in the urban roads and the declining quality of the public transport service has incurred a major negative impact on the economic performance, livability and environmental quality of the region. (Jayasinghe,A., Sano,K., Kasemsri,R., Nishiuchi,H.,2016).

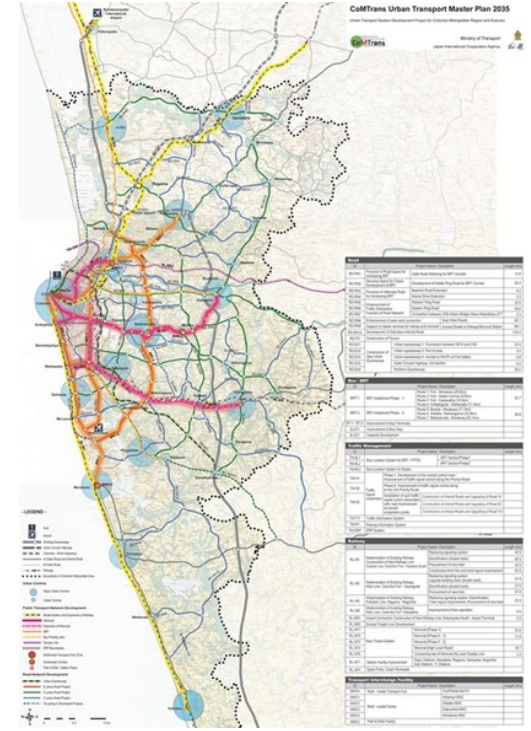

Figure 1: Colombo Metropolitan Region

Source: (Department of Transport \& Logistics Management, University of Moratuwa \& Japan International Cooperation Agency (JICA), 2015)

\subsection{Relationships among Land Use, Transport and Energy Consumption}

Infrastructure projects are catalysts for a city's development. In the conventional planning approach, the structural infrastructure developments has an approach of cluster and connect model.

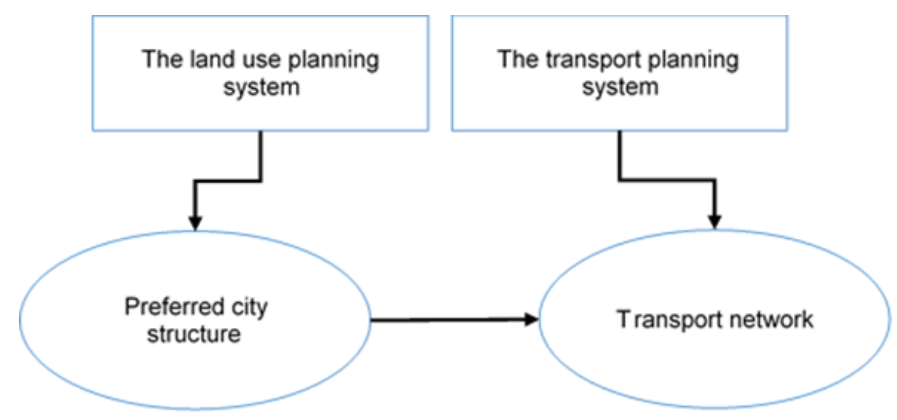

Figure 2: Traditional approach of integrated transport planning (Australian Transport Council, 2006)

However, since the traditional approach (Figure 2) resulted a less energy efficient functionality, an integrated long term approach was introduced (Figure 3) (Australian Transport Council, 2006). The land use and transport infrastructure developments are integrated along the identification of corridors of demand. The cluster and connect model is an important approach in the micro level planning. This approach has a general place-making focus by consolidating community facilities around public transport. However, the system does not facilitate the potential of city shaping ability of the transportation. Therefore, a modern approach for integrating transport planning was adopted to the field of urban planning where the transportation is considered as a main factor of driving the city's movement. In this modern approach optional land use patterns are evaluated along the demand corridors which highlights the aspects of density and mixed use development. 


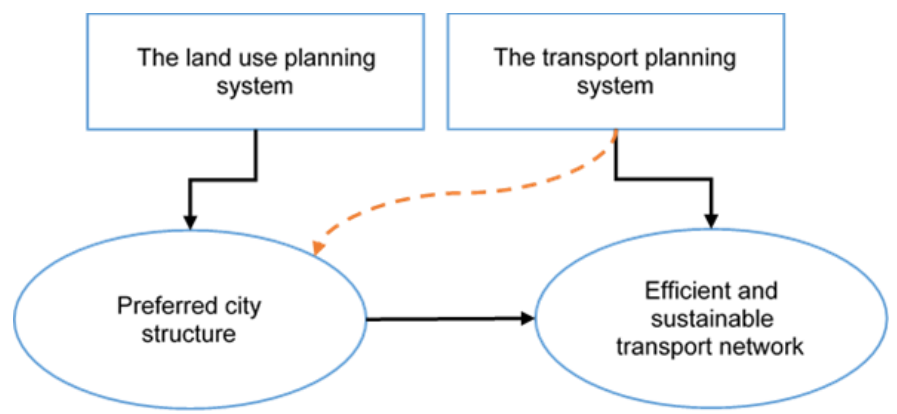

Figure 3: Modern approach for integrated transport planning (Australian Transport Council, 2006)

\subsection{Integrated Approach towards Land Use and Transport Planning}

The modern planning practices are adopting the development of mixed use communities and multimodal transport systems to relate transportation modes to building types being used. In the United States, it is referred as "compact, transit accessible, pedestrian oriented, mixed use development patterns and land reuse epitomize the application of the principles of smart growth" (Inturri, Ignaccolo, Le Pira, Caprì, \& Giuffrida, 2017). The Transit Oriented Developments (TOD) is another widely adopted practice of developing higher density developments closer to the transit destinations where walking intentions are better served. Hong Kong, Curitiba and Tokyo are some of the successful examples of TOD adopted cities. In the above-mentioned cities, automobiles have been deceased by $20-25 \%$ with the introduction of the TOD pattern (He, He, He, \& Zhang, 2007).

\subsection{The Relationship between City Size and Transport Related Energy Consumption}

The energy utilized in the transportation sector against the urban sprawl can be measured as follows. Considering the Vehicle Miles Travelled (VMT), it has been concluded that, once the density is increased the travel distances are shortened and the use of public transportation and walking is increased. Also, the infrastructure and public services development costs are comparatively low in the concentrated development due to the scale of economies (Rickaby, 1987). In terms of energy efficiency high density multinuclear urban forms have been identified as better configurations (Shim, Rhee, Ahn, \& Chung, 2006).

Reducing the number of trips made in a city can be considered as one of the ways of reducing transport related cost. Reducing the average length per trip also can be considered since it directly effects on the city congestion levels. Longer trips can be expected in cities where urban sprawl is higher in extent while compact cities generate shorter trips in length. The widelypracticed approach to control the traffic demand in a city is avoid-Shift-Improve principle.
Avoid-Shift-Improve action seeks possible opportunities for people to change from using private vehicles to public transportation and non-motorized transportation which are more efficient in urban space occupying, fuel consumption and emission of pollutants (ESMAP (The Energy Sector Management Assistance Program), 2014).

The mentioned approaches for integrated transport and land use planning comprehensively concludes the framework for such approaches and energy reduction. Further, the models and frameworks consist of a large amount hypotheses and assumptions (I.e. concentric city and constant congestion levels in Two model analyses of the urban structure of minimal transportation energy consumption (Akisawa \& Kaya, 1998) and Six Settlement Patterns in Six Settlement Patterns Compared (Rickaby, 1987)). The integrated approach of balancing job-house amounts and transport planning will compile a comprehensive mechanism to deploy the integrated land use and transport planning into ground reality.

\section{Research Design}

The prime objective of the research study is to develop a method to calculate the most suitable job-house ratio for the identified TAZ which can maintain the traffic flow in the road network under the standards of Level of Service (LoS). The identified traffic values can be used to calculate the variation of energy consumption in the particular flow of traffic.

\subsection{Similar models on Transport and Land use modeling}

3.1.1. Calculating Minimum Energy Urban Layouts with Mathematical Programming and Monte Carlo Analysis Techniques

The study has identified four modeling approaches. Regression, optimization, aggregation and disaggregation are the approaches that have been practically used in finding answers for policy questions on city expansion, people's choices on living and working, mode of transportation in urban travel. In particular optimization modeling is a useful method for defining minimum energy benchmarks (Keirstead \& Shah, 2011).

\subsubsection{Two Model Analyses of the Urban Structure of Minimal Transportation Energy Consumption}

The Minimal Tip Length model considers a constant congestion city and focuses on reducing the transportation trip length to minimize the energy consumption and wastage. The other model is Minimal Fuel model with the prime consideration of reducing energy consumption. This is achieved via operating a mechanism to trade off trip length with fuel consumption (Akisawa \& Kaya, 1998). 
3.1.3. Modelling Regional Energy-Use: A Land-Use, Transport, and Energy-Evaluation Model

This model is consisted of two sub models integrating land use and transportation. Two aspects of the urban energy use have been evaluated in the model. Static or permanent character: the energy used in operations of physical infrastructure systems. Flow and activity based character: the energy consumed at fixed locations (residential, industrial) and energy consumed in the people's interaction patterns (movements of people or commodities) (Rickaby, 1987).

\subsubsection{The Four Step Model}

The Four Step Model (FSM) provides a method to determine commuter flows which are of equilibrium states. The FSM is useful in handling complex transportation simulations. As mentioned in the diagram the model follows a series of steps to calculate the number of flows.

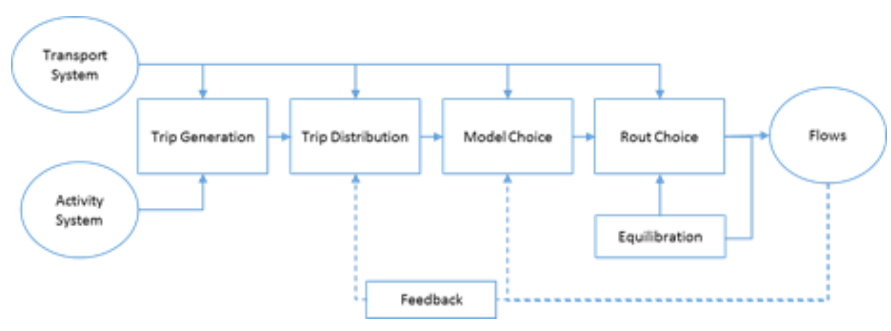

Figure 4: The four step model

The first step of the model is to calculate the trip production in a particular zone based on the resident population. The trip productions and attractions are calculated separately. The trip distribution stage allocates the identified trip calculations to the respective zone to demonstrate the travel demand. The mode choice reflects the relative proportion of the alternative mode utilization. The route choice assigns the trips to the respective mode specific networks (G. McNally, 2007).

\subsection{Research Methodology}

The research methodology is focused on optimizing the road link traffic flow to better serve the LoS of the road network and to calculate the balanced Job-House ratio for each analysis zone.

\subsubsection{Job-House Ratio}

The job-housing balance rational refers to the geographic relationship between the amount of jobs and houses available within a considered spatial context. The balanced job-housing ratio can be considered when the resident workers can approach to their working place within a reasonable travel distance. In 1994 the entropy index was used to identify the level of heterogeneity among land uses. The entropy index involves a detailed land use characteristics such as family members, offices, level of services, institutional and industrial areas. The highly mobile employment locations and residential locations keeps the job housing ratio balanced over time (Peng, 1997).

\subsection{Delineating Traffic Analysis Zones (TAZ)}

The initial stage of the process is defining the Traffic Analysis Zone (TAZ). The TAZ is considered as the micro feature for analyzing the travel demand forecasting. In the study, the TAZ is defined using the Theissen Polygon tool in Arc Geographic Information System (GIS) software. The Theissen Polygons are constructed based on the Delaunay triangulation network theory.

The base of constructing the TAZs (Figure 5) is the nodes which are placed based on the transportation network intersections. Network Analysis Tool in GIS can be used to perform the task. The Theissen polygon demarcates the population fallen into a particular zone for the purpose of trip transactions.

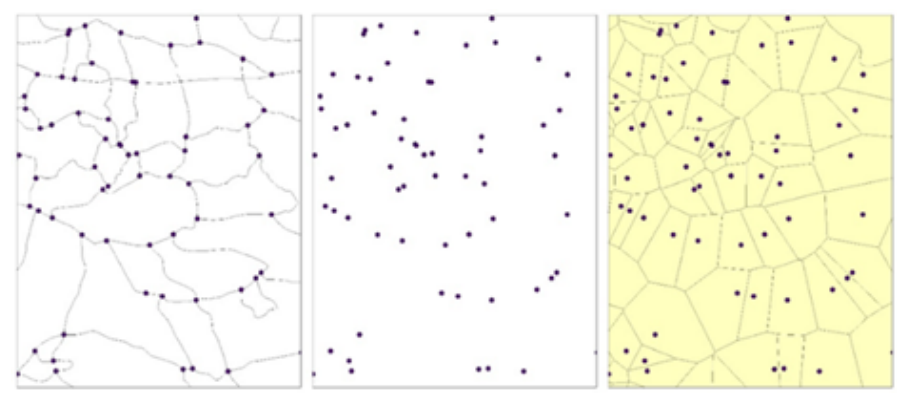

Figure 5: Formulation of Traffic Analysis Zones (TAZ)

\subsection{Calculation of Total Trip Generation and Attraction}

Using the following models for population and employment the amount of trip generation and attraction is calculated for each zone. The density of economically active population and employment opportunities in administrative levels are considered for the calculation of trip generation and attraction in TAZ. The economically active percentage of the population is considered to calculate the home based work trips and to calculate the number of motorized trips, the vehicle registration percentage is considered in the study area.

Zonal Trip generation Model

Ln $($ Trips Produced $)=1.0229$ x Ln (Population $)$

Zonal trip attraction model

\section{Ln $($ Trips Attraction $)=0.9384 \times$ Ln $($ Employment $)+$ 0.96}

(Gulden, Goates, \& Ewing, 2013)

\subsection{Application of Gravity Model for the Generation of Origin-Destination Matrix}

The Gravity model is used to calculate the number of trip distribution among the intersections. Several iterations are used to generalize the result of trip generation and attraction. It is assumed that the people's travel behaviors 
are associated with the shortest paths. Therefore, the Graph theory is used to identify the shortest paths among the each intersections. The Network Analysis tool in the Arc GIS software is used for the calculation of shortest paths.
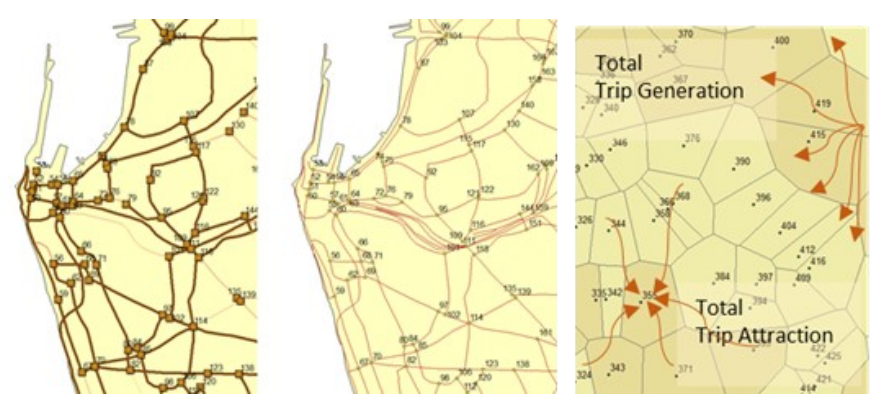

Figure 6: Calculation of shortest paths among nodes

\subsubsection{Gravity Model}

The Gravity Model (GM) is formulated based on Newton's concept of gravity. The model assumes that the trips being transferred among zones in an area is dependent based on the relative attraction and the geographic distance between them. The role of spatial distance adjusts the relative attraction of zones for its capacity.

$T_{i-j}=K P_{i} A_{j} / d_{i j}^{n}$

$\mathrm{T}_{i-j}=$ Trips between zone $\mathrm{i}$ and $\mathrm{j}$

$\mathrm{P}_{i}=$ Trips produced in zone $\mathrm{I}$

$A_{j}=$ Trips attracted to zone $\mathrm{j}$

$d_{i j}^{n}=$ Distance between zone $\mathrm{i}$ and zone $\mathrm{j}$

$\mathrm{K}=$ Constant independent of $\mathrm{i}$

$\mathrm{n} \quad=$ an exponential constant (varies between 1 and 3 )

(Kadiyali, 2013)

\subsection{Graph theory}

A graph is identified by vertices and edges connecting the vertices. In transportation, the Graph theory is used for routing analysis and networks analysis (Jayasinghe, A., Sano, K., \& Rattanaporn, K., 2017). In this study the application of minimum cost flow solution is used to identify the shortest possible paths among the intersections (Monteiro, Robertson, \& Atkinson, 2014).

\subsection{Route Assignment}

The traffic volumes are assigned to each link as mentioned below;

\begin{tabular}{|c|c|c|}
\hline $\begin{array}{c}\text { From } \\
\text { zone } \\
\text { cen- } \\
\text { troid }\end{array}$ & $\begin{array}{c}\text { To } \\
\text { zone } \\
\text { cen- } \\
\text { troid }\end{array}$ & $\begin{array}{c}\text { Traffic vol- } \\
\text { ume } \\
\text { (vehicles/ } \\
\text { hour) }\end{array}$ \\
\hline 1 & 2 & 2500 \\
\hline 1 & 3 & 4500 \\
\hline 1 & 4 & 3500 \\
\hline
\end{tabular}

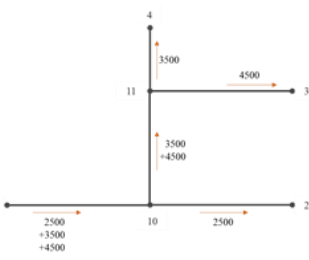

To identify the road link volume the cumulative value of each link along its segments are added. Once the chart is prepared the total along the columns give the volume of each segment.

Table 1: Traffic volume

\begin{tabular}{|c|r|r|}
\hline Link & Traffic Flow & Total Volume \\
\hline $1-10$ & $2500+3500+4500$ & 11500 \\
\hline $10-2$ & 2500 & 2500 \\
\hline $10-11$ & $3500+4500$ & 8000 \\
\hline $11-3$ & 4500 & 4500 \\
\hline $11-4$ & 3500 & 3500 \\
\hline
\end{tabular}

\subsection{Analysis of the Level of Service (LoS)}

The purpose of LOS is to evaluate the traffic service quality with a given flow rate of traffic. For a given road the capacity is constant, but the actual flow rate varies based on the functional population of the area. The quality of the traffic is divided into six categories ranging from level A to Level F (Level A being the best quality of traffic with a free flow of traffic and Level $\mathrm{F}$ being the worst quality of traffic). The main criteria considered in the LoS estimation are speed and travel time, density, and delay.

In planning practices the Volume to Capacity ratio (V/C) is used to generalize the result of LoS. In V/C ratio, volume (demand) is compared to the estimated capacity of each road link during the peak period. The VMT is calculated by multiplying the amount of trip generation by their respective length of the shortest paths (National Research Council (U.S.), 2000).

\subsection{Recalculation of the O-D Matrix}

Based on the V/C value the roads are categorized and identified in order of their quality of traffic level. Further it is identified the levels where the quality has to be improved or can be maintained. Accordingly, for each segment a moderated value for $\mathrm{V} / \mathrm{C}$ is identified based on its percentage contribution for overall traffic congestion.

Based on the moderated $\mathrm{V} / \mathrm{C}$ ratio in the roads new trip generation and attraction values are determined. Using the zonal models, new population and employment amounts are calculated. The output of the above calculation provides the required amount of employment opportunities and labour force participation in a particular area. Using the following formula the values can be concluded to a ratio which can be applied to the respective analysis zones in terms of mobilizing the population and employment to maintain a traffic congestion free road environment.

Iob - House Ratio $=\frac{\text { Available Employment Opportunities }}{\text { Labour Force Population }}$ 
Table 2: Level of Service

\begin{tabular}{|c|c|c|c|c|r|}
\hline $\begin{array}{c}\text { LAOS } \\
\text { Main roads }\end{array}$ & Volume & Capacity & $\begin{array}{c}\text { Travel } \\
\text { Speed }\end{array}$ & V/C & State of improvement \\
\hline A & 2100 & 6000 & 65 & 0.35 & Possible to accommodate more vehicles \\
\hline B & 3300 & 6000 & 60 & 0.55 & Quality should be maintained \\
\hline C & 4620 & 6000 & 55 & 0.77 & Quality should be maintained \\
\hline D & 5520 & 6000 & 50 & 0.92 & Quality improvements are required \\
\hline E & 6000 & 6000 & 40 & 1.0 & Quality improvements are required \\
\hline F & $>6000$ & 6000 & 20 & $>1.0$ & \\
\hline
\end{tabular}

(National Research Council (U.S.), 2000)

\section{Analysis and Results}

\subsection{Introduction}

The Colombo district as mentioned previously is liable for the highest agglomeration point of Sri Lanka. This is caused mainly because of its geographic location and lately added elements. Since its significance of the geographic location, Sri Lanka's international relationships are initiated at this point. The infrastructure concentration has caused to increase its accessibility and therefore the people's retention rate has risen within the district.

\section{District: Colombo}

Area: $679.6 \mathrm{Km} 2$

No. of GN/DS Divisions: 558/13

Population: $1,820,445$

Employment: 4,407,768

Floating Population: 1 million approx.

Trip Attraction Amount: 6,461,866

Trip Generation Amount: 2,202,898

Trip Length Per Capita: 23.74 km

Average Job House Ratio: 2.42

Net Migration Rate: 67.1

Source: (Department of Census and Statistics, Sri Lanka, 2014)

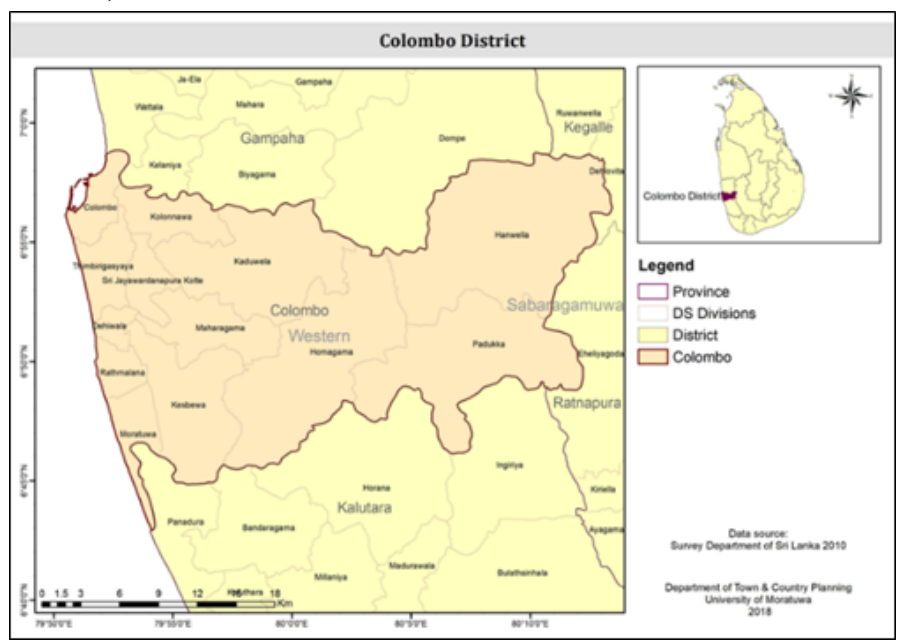

Figure 7: Colombo District

\subsection{Case study area}

Colombo district (Figure 7) was used for the purpose of studying the identified model. The area was subdivided into 1800 zones based on the junctions formed at the intersections of $\mathrm{A}, \mathrm{B}$ and minor roads. The purpose of sub dividing the region is to obtain a better understanding about the people's travel behaviors. The nodes at the intersections known as "Centroids" are considered as the trip generation and attraction points with respect to the base area. Once the population and employment details were assigned into the identified zones, the following result was obtained.

\subsection{Population Density and Trip Generation}

The population agglomerates towards the Central Business Area (Fort, Pettah and immediate surrounding, CBA) and towards Hanwella Divisional Secretariat Division the population is comparatively dispersed. In values the population density at $\mathrm{CAB}$ is between 8,000 14,000 persons/sq.km $\left(\begin{array}{lll}80 & -140 \mathrm{p} / \mathrm{Ha}\end{array}\right)$ and towards Hanwella DSD it drops down to around 2,000 p/sq.km $(20 \mathrm{p} / \mathrm{Ha})$. The condominium development and high rises within the CBA annually cause for a growth of $12.1 \%$ (Department of Census and Statistics, Sri Lanka, 2014) in the floating population towards the CBA causing for an increased population density.

Similarly as the population and employment distribution, the trip generation also has an uneven distribution among zones. As per the calculations the trip generation rate is 20,000 average trips per day / 550 average trips per Ha in the red coloured areas in the map (Figure 8) cum the total VTM in those zones also are high compared to other zones. This scenario is caused since the resident population is higher in the blue coloured zone which cause for lengthier vehicle trips (VMT per capita $23 \mathrm{~km}$ ).

\subsection{Employment Density and Trip Attraction}

The Colombo district is consisted of a vast disparity in terms of the employment distribution. The annual growth rate in the employment availability is $9.4 \%$ in CBA and particular concentration is seen at the Fort, Pettah and adjacent DS divisions (Department of Census and Statistics, 2016). In particular, the employment density in 
the CBA varies between 20,000 - 30,000 employements/ sq.km (200-300 per $\mathrm{Ha})$ and the distant areas are occupied with a lower rate whereas 5,000 - 10,000 (50100 per Ha) employments/sq.km.

Since the density of employment opportunities is found high at the CBA, it attracts most of the trips generated from the TAZs (The Colombo Municipal Council attracts $26 \%$ of the total trips generated in the Colombo district). The agglomeration of economies caused for this concentration of employment opportunities and consequent trip attractions. The office complexes, administrative firms and commercial activities which are situated close to CBA generate a growing rate $(9.4 \%)$ of employment opportunities.

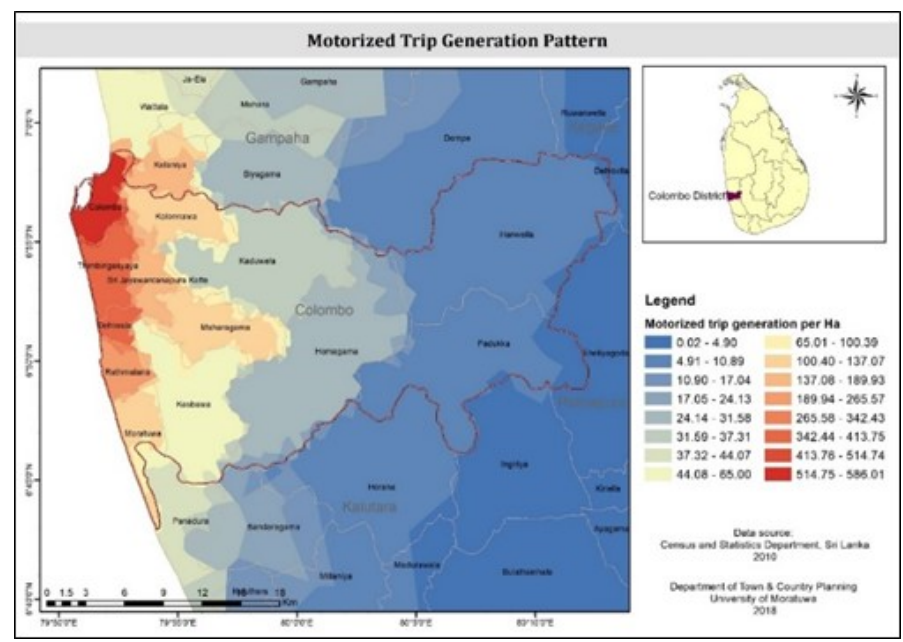

Figure 8: Motorized trip generation pattern

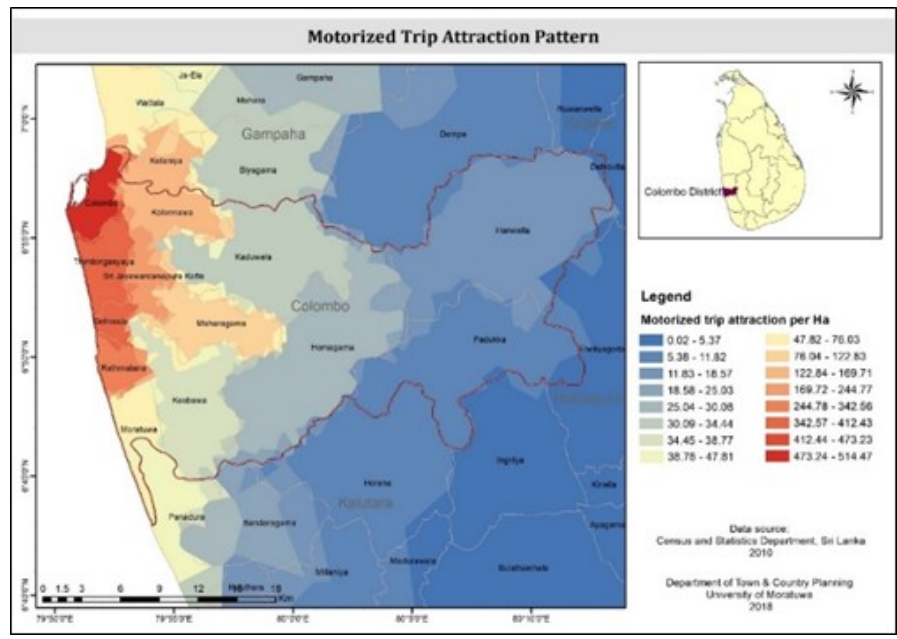

Figure 9: Motorized trip attraction pattern

\subsection{Existing Job-House Ratio in Colombo District}

The red coloured areas mentioned in the map (Figure 10) demonstrates where the job-house ratio is comparatively higher (Employment level is 9 times more than the resident economically active population). The blue areas demonstrates a lower level of job-house ratio stating a high amount of resident population than the employment availability. Within the zone the job-house ratio varies between $0.5-9.3$ demonstrating that the job-house balance is significantly uneven. This uneven distribution of job-house ratio causes for lengthier trip transactions among the zones based on the people's willingness to travel for longer distances for the purpose of employment destination irrespective of the travel time and distance. As per the calculations the VMT per capita significantly depends on the Job-house ratio $(\mathrm{R} 2=0.593)$. The relationship between the Job-house ratio and VMT per capita is demonstrated by the given formula. $\mathrm{Y}=0.01 \mathrm{X}^{2}$ - 0.0698X + 9.1032 where $Y-$ Job-House ratio for a given TAZ, $\mathrm{X}$ - VMT per capita.

Accordingly, TAZs with comparatively higher Job-house ratio and lower Job-house ratio are accountable for lengthier VMT per capita (Figure 11).

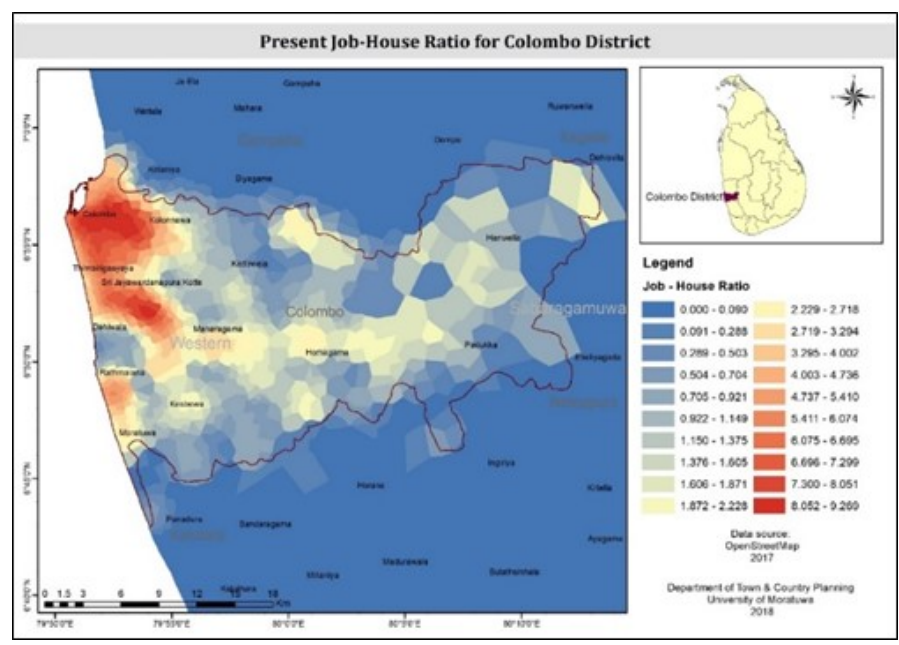

Figure 10: Present Job-House ratio

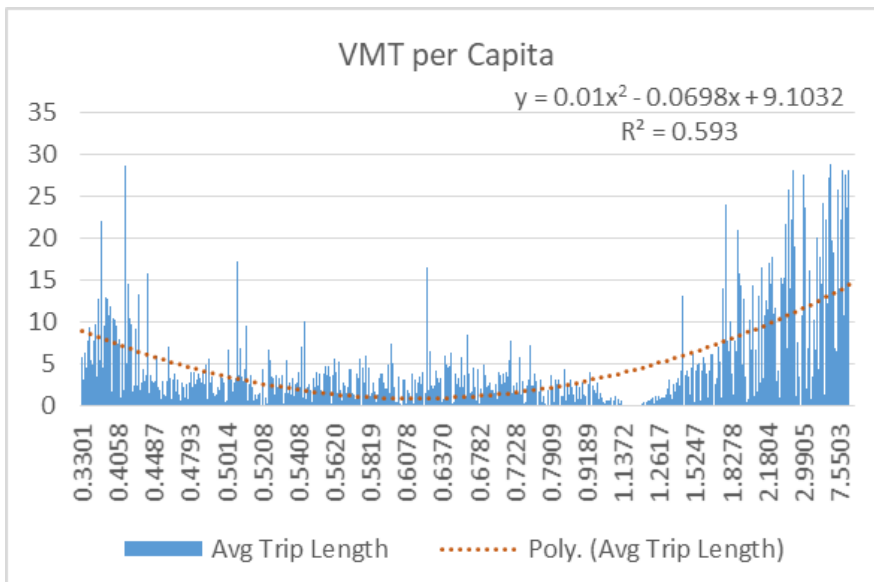

Figure 11: Relationship between $\mathrm{J} / \mathrm{H}$ ratio and VMT per capita

This disparity of job-house ratio has caused for a higher amount of VMT. As an average, trips of $30-50 \mathrm{~km}$ length occurs at a daily rate of 150,000 from the distant TAZs. Since the job availability is low in the distance areas from CBA a larger portion of population $(60 \%)$ tends to travel a distance of $30-50 \mathrm{~km}$ searching for better job opportunities in CBA.

This level of higher VMT originated at the hinterland towards the central business area is caused for a higher amount of fuel consumption and wastage. At an average speed of $20 \mathrm{~km} / \mathrm{h}$ a vehicle consumes $140 \mathrm{ml}$ (approx.) 
per $1 \mathrm{~km}$. It is twice as the amount in a standard situation (Biggs \& Akcelik, 1985).

Further, the traffic flow concentrated into a particular zone causes for a higher trip transactions along the road network, therefore the level of congestion caused to grow during peak hours.

The Figure 12 demonstrates that the LoS of the road links connecting hinterland and CBA is much more congested (more than $60 \%$ of its design capacity) than the roads distributed in hinterland. The LoS of the roads near CBA demonstrates $\mathrm{E}-\mathrm{F}$ values which represent the $\mathrm{V} / \mathrm{C}$ is 1 and more. The speed varies between $17-20$ $\mathrm{km} / \mathrm{h}$. The lowest level of speeds is caused because of the less spacing between vehicles and higher amount of queue length.

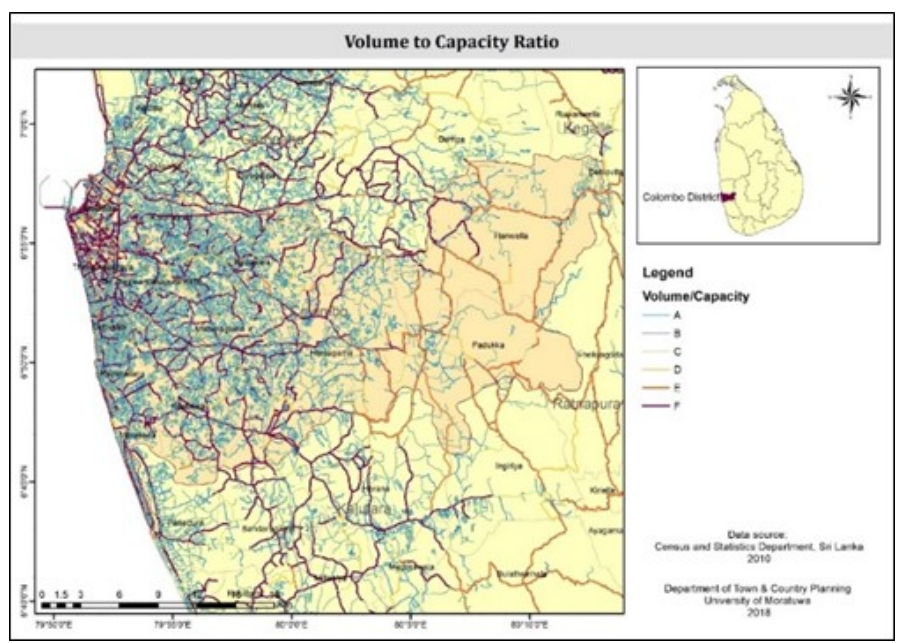

Figure 12: Volume to capacity ratio

The Colombo district attracts traffic flows from almost all the districts in Sri Lanka. Many of the A class, B class, Expressways and minor roads are destined at the Colombo district causing for 10 million passenger trips towards the zone. The design capacities of the Colombo district roads can bear only an amount of 3.8 million PCU under the design speed and zero congestion level. However, there is an exceeded amount of 4.7 million traffic inside the Colombo district causing to overdue the road holding capacities and congestion levels.

\subsection{Proportionate Trip Balancing}

Considering the LoS of the road links and based on the level of congestion the each segment generates new combination of employment and population is calculated for each TAZ to reduce the congestion in each segment and to improve the LoS in each segment. It is considered while calculations to maintain the LoS in roads segments in $\mathrm{B}, \mathrm{C} \& \mathrm{D}$ levels which makes a convenient environment for road users.

Figure 13 and 14 demonstrate the proposed distributions for residence and employment locations. The maximum proposed population density is 200 persons per hectare (20000 per sq.km) and it is distributed over the district.
Similarly, the employment density also limited to 400 employments per hectare (40000 per sq.km) having a dissolved distribution. The mentioned scenario enables a new job-house ratio as mentioned in the figure 15 .

\subsection{Proposed employment clusters based on job- house ratio}

The proposed job-house ratio is formulated based on the estimated population and employment combination to each zone. Unlike the previous context, the present context has a balanced job-house ratio which demonstrates an even distribution in the employment and population in zones. The maximum value of the ratio is 3.8 and the rest lay below that. This scenario demonstrates that the job-house balance does not vary drastically causing exaggerated trip generations or attractions. Therefore, the traffic volume on any road link stays below the proposed design capacities of the roads. As per the calculations the total vehicle miles travelled have been reduced by $43 \%$ based on the reformulation of the job-housing locations.

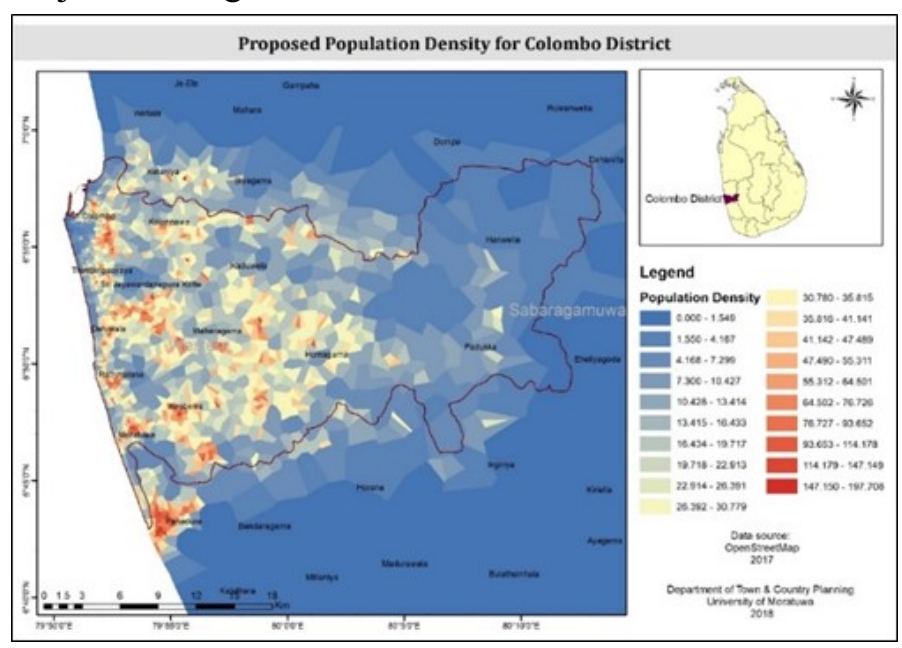

Figure 13: Proposed population density

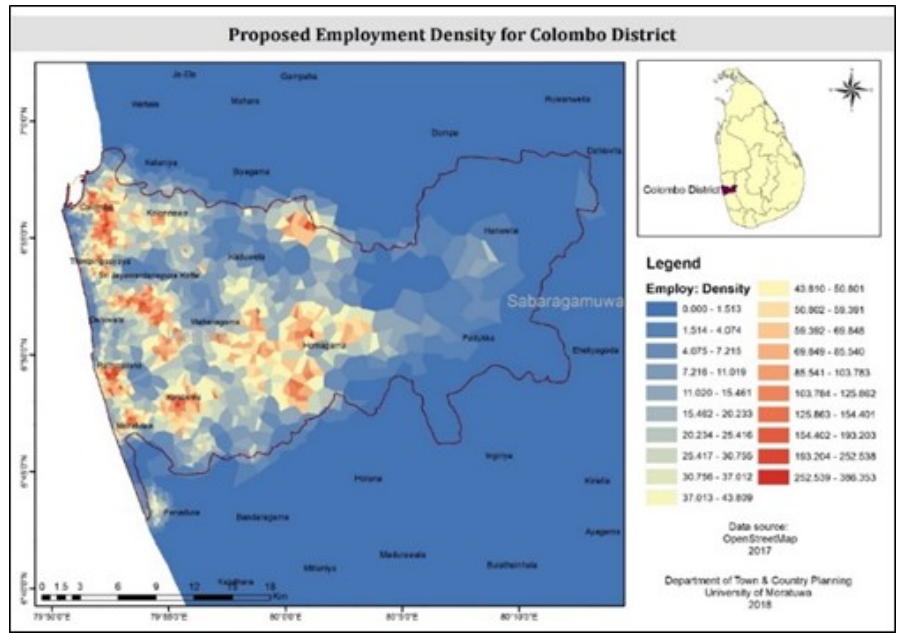

Figure 14: Proposed employment density

The figure 16 demonstrates the spatial structure for proposed employment hotspots. The $1^{\text {st }}$ order locations are Homagama and Kaduwela DS divisions and the 


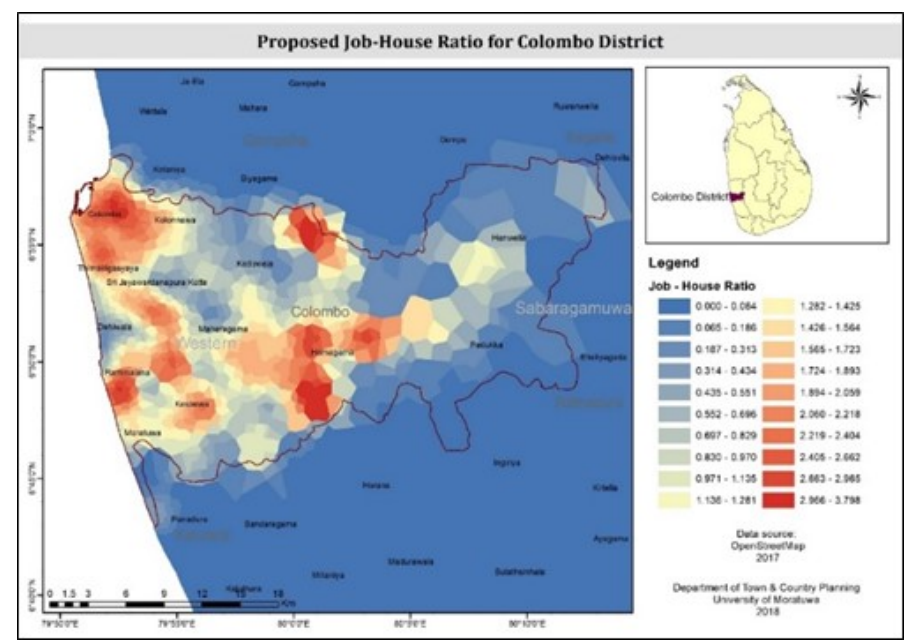

Figure 15: Proposed Job-House ratio

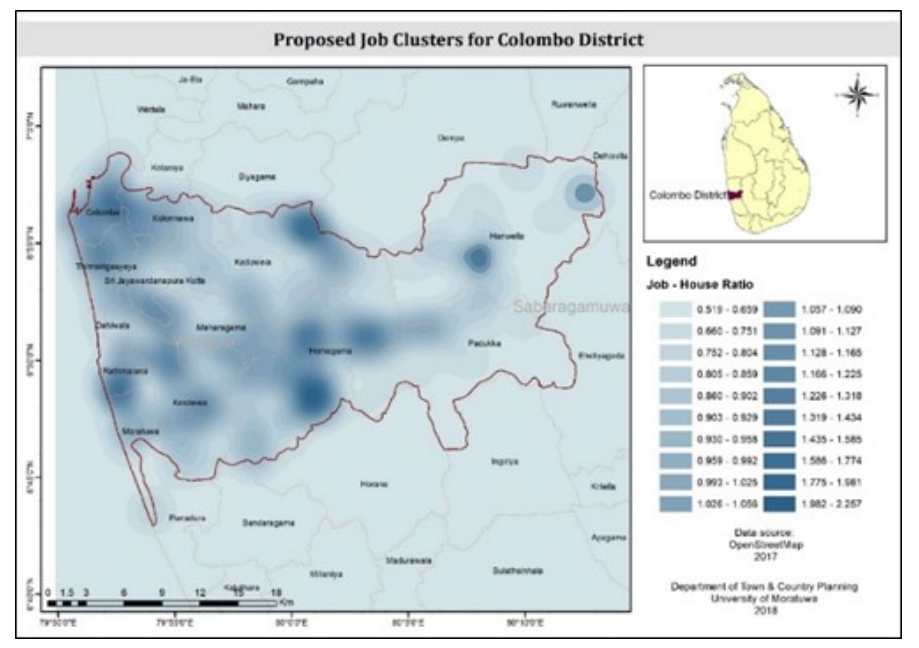

Figure 16: Proposed job clusters for Colombo

second order locations are Rathmalana, Colombo and Hanwella DS divisions.

With the new proposed job housing scenario, it is clearly demonstrated that the passenger travel distances are comparatively reduced. In the previous case, the total VMT was recorded as $8,318,764 \mathrm{~km}$ and with the proposed context it has reduced down to $3,609,670 \mathrm{~km}$. It is a reduction of $43 \%$ of the total VMT in the city and VMT per capita is reduced to $13.9 \mathrm{~km}$ from $23 \mathrm{~km}$. This reduction in the trip distribution caused for the improvement in the LoS limited to the maximum level of D. This scenario saves the average fuel consumption by $22 \%$.

\section{Conclusion and Recommendations}

The research study is predominantly carried out on modelling a land use and transport integrated system to minimize the energy consumption and wastage caused by the traffic congestion in urban context. Following the research study, the job-housing ratio was identified as a critical factor which drives the travel pattern in any spatial context and therefore, the energy consumption in the city is driven by the traffic flow and the traffic congestion levels.
The research study is followed by important key findings regarding the job-house balance in any urban context as well as the case study area. Firstly, the job-house ratio in Colombo district varies from $0.5-9.3$. There is no unique or even distribution in the population or employment which has led the Colombo urban context into a mismatching land use and transport system. The road network of the city of Colombo area is over congested during the peak time with the transferring rate of traffic to distant localities ( $\operatorname{LoS}$ is identified at D, E and F). This scenario causes for a colossal amount of loss in the energy, passenger time and also causes directly to the air pollution and temperature. Finally, a new ratio of 0.5 to 3.8 which is evenly distributed among zones and fulfilling the requirement of free flow in every road link.

The research study could identify an approach for solving the above-mentioned situations via providing an integrated solution in the transport and land use systems. Since the number of trips generated in the Colombo district is dominantly driven by the home-based work trips, the study proposes a suitable combination in the jobs and residence locations for the district based on demarcated zones. The proposed job-house balance ratio is derived based on the zero congestion levels in the road network. According to the proposed V/C for the road links, the amount of affordable trip generations is estimated as a portion of the zone population. Finally, each and every zone is assigned with a new amount of population and employment where the amount of newly generated trips of attracted trip do not contribute to the traffic congestion increment in any given road link.

The fundamental recommendation of the research study is to have the job-house balancing mechanism incorporated into the planning process. Even though the model provides a scientific input to balance the job house locations, the existing situation can be very much deviated from the result. Therefore, the model requires a thorough analysis of the people's behaviors and the existing land use configuration. Unless, the result shall not provide a feasible output to the consumer. To further develop the model an automated programming system shall be incorporated which shall be user friendly and can be given for the local authorities for their practice. Also, the research study can be further carried out to incorporate the capacities at the road junctions. Because, the congestion occurs not only because of the road capacity but also because of the junction capacity. Therefore, the road junction capacity also should be incorporated into the model to obtain a better feasible result. 


\section{References}

Akisawa, A., \& Kaya, Y. (1998). Two model analyses of the urban structure of minimal transportation energy consumption. Applied Energy, 61(1), 25-39. https://doi.org/10.1016/S0306-2619(98)00036-1

Australian Transport Council. (2006). National Guidelines for Transport System Management in Australia: 2006. Barton, A.C.T.: Australian Transport Council.

Biggs, D. C., \& Akcelik, R. (1985). An Interpretation of the Parameters in the Simple Average Travel Speed Model of Fuel Consumption. A ustralian Road Research Board, 15, 46-49.

Department of Census and Statistics. (2016). Sri Lanka Labour Force Survey A nnual Report - 2016.

Department of Census and Statistics, Sri Lanka (Ed.). (2014). Census of population and housing 2012: key findings. Colombo: Department of Census and Statistics, Ministry of Finance and Planning.

Department of Transport \& Logistics Management, University of Moratuwa, \& Japan International Cooperation Agency (JICA). (2015). Colombo Metropolitan Region Transport Master Plan (No. 7). Ministry of Internal Transport Colombo - Sri Lanka.

ESMAP (The Energy Sector Management Assistance Program). (2014). Toward Sustainable and Energy Efficient Urban Transport. Washington: The World Bank. Retrieved from http://www.africancityenergy.org/uploads/ resource_28.pdf

G. McNally, M., \& Button, K. J. (Eds.). (2007). The Four-Step Model, in David A. Hensher, Kenneth J. Button (ed.) Handbook of Transport Modelling (2nd ed., Vol. 1). Emerald Group Publishing Limited. https:// doi.org/10.1108/9780857245670

Gulden, J., Goates, J. P., \& Ewing, R. (2013). Mixed-Use Development Trip Generation Model. Transportation Research Record: Journal of the Transportation Research Board, 2344(1), 98-106. https://doi.org/10.3141/2344-11

He, M., He, M., He, Z., \& Zhang, Z. (2007). Sustainable Energy Development in Urban Transportation System under TOD Pattern: a Case Study in China, 8.

Inturri, G., Ignaccolo, M., Le Pira, M., Caprì, S., \& Giuffrida, N. (2017). Influence of Accessibility, Land Use and Transport Policies on the Transport Energy Dependence of a City. Transportation Research Procedia, 25, 3273-3285. https://doi.org/10.1016/j.trpro.2017.05.165

Jayasinghe, A., Sano, K., \& Rattanaporn, K. (2017). Application for developing countries: Estimating trip attraction in urban zones based on centrality. Journal of Traffic and Transportation Engineering (English Edition), 4(5), 464476.

Jayasinghe, A., Sano, K., Kasemsri, R., \& Nishiuchi, H. (2016). Travelers' Route Choice: Comparing Relative Importance of Metric, Topological and Geometric Distance. Procedia engineering, 142, 18-25.

Kadiyali, L. R. (2013). Traffic engineering and transport planning.

Keirstead, J., \& Shah, N. (2011). Calculating minimum energy urban layouts with mathematical programming and Monte Carlo analysis techniques. Computers, Environment and Urban Systems, 35(5), 368-377. https:// doi.org/10.1016/j.compenvurbsys.2010.12.005

Kumarage, P. A. (2013). Massive Rs 32 bln loss due to traffic congestion:Transport expert. Retrieved April 27, 2018, from http://www.sundaytimes.lk/110313/BusinessTimes/bt03.html

Ministry of Megapolis and Western Region Development. (2016). Transport Proposal for Western Region Megapolis Development Project. Colombo: Ministry of Megapolis and Western Region Development. Colombo: Ministry of Megapolis and Western Region Development. Retrieved from https://drive.google.com/file/ d/1HF7JFuYkgIwFA5wfi07GIaHqhv3eHjWR/view?usp=sharing\&usp=embed_facebook

Monteiro, J., Robertson, G., \& Atkinson, B. (2014). NETWORKS IN TRANSPORTATION - THEORY, 21.

National Research Council (U.S.) (Ed.). (2000). Highway capacity manual. Washington, D.C: Transportation Research Board, National Research Council.

Peng, Z.-R. (1997). The Jobs-Housing Balance and Urban Commuting. Urban Studies, 34(8), 1215-1235. https:// doi.org/10.1080/0042098975600 
Rickaby, P. A. (1987). Six settlement patterns compared. Environment and Planning B: Planning and Design, 14(2), 193-223. https://doi.org/10.1068/b140193

Shim, G.-E., Rhee, S.-M., Ahn, K.-H., \& Chung, S.-B. (2006). The relationship between the characteristics of transportation energy consumption and urban form. The Annals of Regional Science, 40(2), 351-367. https:// doi.org/10.1007/s00168-005-0051-5

UN, Department of Economic and Social Affairs. (2014). World urbanization prospects: 2014. United Nations, Department of Economic and Social Affairs, Population Division.

World Bank, \& United Nations Human Settlements Programme (Eds.). (2012). Turning Sri Lanka's urban vision into policy and action. Colombo: The World Bank Colombo Office. 